\title{
Efficacy and safety of cold forceps polypectomy utilizing the jumbo cup: a prospective study
}

\author{
Hiroshi Hasegawa ${ }^{1,2}$, Shigeki Bamba ${ }^{3}$, Kenichiro Takahashi ${ }^{1}$, Masaki Murata ${ }^{1}$, Taketo Otsuka ${ }^{4}$, Hiroshi Matsumoto ${ }^{4}$, \\ Takehide Fujimoto ${ }^{1}$, Rie Osaki ${ }^{1}$, Hirotsugu Imaeda ${ }^{1}$, Atsushi Nishida ${ }^{1}$, Hiromitsu Ban $^{5}$, Ayano Sonoda ${ }^{1}$, \\ Osamu Inatomi ${ }^{1}$, Masaya Sasaki ${ }^{3}$, Mitsushige Sugimoto ${ }^{4}$, Akira Andoh ${ }^{1}$ \\ ${ }^{I}$ Division of Gastroenterology, Shiga University of Medical Science, Otsu; ${ }^{2}$ Division of Gastroenterology, Japan Community Health Care \\ Organization Shiga Hospital, Otsu; Divisions of ${ }^{3}$ Clinical Nutrition and ${ }^{4}$ Digestive Endoscopy, Shiga University of Medical Science, Otsu; \\ ${ }^{5}$ Division of Gastroenterology, Kusatsu General Hospital, Kusatsu, Japan
}

Background/Aims: There are few prospective studies on cold forceps polypectomy (CFP) using jumbo cup forceps. Therefore, we examined patients with diminutive polyps ( $5 \mathrm{~mm}$ or smaller) treated with CFP using jumbo cup forceps to achieve an adenoma-free colon and also assessed the safety of the procedure and the recurrence rate of missed or residual polyp after CFP by performing follow-up colonoscopy 1 year later. Methods: We included patients with up to 5 adenomas removed at initial colonoscopy and analyzed data from a total of 361 patients with 573 adenomas. One-year follow-up colonoscopy was performed in 165 patients, at which 251 lesions were confirmed. Results: The one-bite resection rate with CFP was highest for lesions $3 \mathrm{~mm}$ or smaller and decreased significantly with increasing lesion size. Post-procedural hemorrhage was observed in 1 of 573 lesions $(0.17 \%)$. No perforation was noted. The definite recurrence rate was $0.8 \%(2 / 251$ lesions). The probable recurrence rate, which was defined as recurrence in the same colorectal segment, was $17 \%$. Adenoma-free colon was achieved in $55 \%$ of patients at initial resection. Multivariate analysis revealed that achievement of an adenoma-free colon was significantly associated with number of adenomas and years of endoscopic experience. Conclusions: CFP using jumbo biopsy forceps was safe and showed a high one-bite resection rate for diminutive lesions of $3 \mathrm{~mm}$ or smaller. The low definite recurrence rate confirms the reliability of CFP using jumbo biopsy forceps. Number of adenomas and years of endoscopic experience were key factors in achieving an adenoma-free colon. (Intest Res 2019;17:265-272)

Key Words: Diminutive polyp; Adenoma; One-bite resection; Recurrence; Hemorrhage

\section{INTRODUCTION}

Colorectal cancer is the 3rd most common cancer in men (746,000 cases, $10.0 \%$ of the total) and the 2 nd most common cancer in women ( 614,000 cases, $9.2 \%$ of the total) worldwide, and approximately half of all patients with colorectal cancer

\footnotetext{
Received July 8, 2018. Revised August 9, 2018. Accepted September 5, 2018. Correspondence to Shigeki Bamba, Division of Clinical Nutrition, Shiga University of Medical Science, Seta-Tsukinowa, Otsu 520-2192, Japan. Tel: +81-77-548-2899, Fax: +81-77-548-2499, E-mail: sb@belle.shiga-med. ac.jp

ORCID Hiroshi Hasegawa (https://orcid.org/0000-0001-9590-5408), Shigeki Bamba (https://orcid.org/0000-0002-4108-5894)
}

will die of it. ${ }^{1}$ The incidence of colon cancer is on the rise and is associated with risk factors such as increasing obesity and westernization of diet characterized by a high fat diet, increased red meat consumption, and low fiber. ${ }^{2}$ Because most colon cancer develops in an adenoma-carcinoma sequence, ${ }^{3}$ removal of premalignant adenomas is recommended. ${ }^{4,5}$

According to the results of the National Polyp Study (NPS) conducted in the United States, the achievement of an adenoma-free colon (or clean colon) suppressed the disease rate of colon cancer by $76 \%$ to $90 \%{ }^{6}$ and also prevented mortality in $53 \%$ of cases. ${ }^{7}$ However, the results from the NPS were based on the presupposition that all adenomatous lesions were re- 
moved. In contrast, the Japanese Guidelines for Treatment of Polyps 2014 state that observation is acceptable for the treatment of small adenomas measuring $5 \mathrm{~mm}$ or less, and management differs depending on the endoscopist or patient background.

Most lesions found on screening colonoscopy are small polyps measuring less than $1 \mathrm{~cm}$, and polyps measuring $5 \mathrm{~mm}$ or less, which are defined as diminutive polyps, ${ }^{8}$ make up the majority of these lesions ${ }^{9}$ and most of them are adenomas. ${ }^{8,10}$ According to the results of initial total colonoscopy in the Japan Polyp Study, from a total 5,168 lesions smaller than $10 \mathrm{~mm}$, 3,827 were diminutive polyps, of which $98.9 \%$ were showed mild to moderate atypia. ${ }^{11}$ Cancer was very rare, with incidence rates of $0.2 \%$ for intraepithelial carcinoma and $0.03 \%$ for carcinoma involving the submucosa. ${ }^{11}$ Although microadenoma can be followed up without being removed because of its low malignant potential, endoscopic polypectomy may be performed, given the evidence obtained from the NPS study, ${ }^{6}$ low compliance with follow-up colonoscopy, ${ }^{12}$ and inadequate consensus about duration of the interval until follow-up colonoscopy when the microadenoma is not removed.

Regarding the removal of diminutive polyps, Uraoka et al..$^{13}$ reported a multicenter prospective study on cold forceps polypectomy (CFP) using jumbo cup forceps for 223 consecutive lesions smaller than $5 \mathrm{~mm}$. Based on magnifying narrow band imaging (NBI), the overall one-bite polypectomy rate was $85 \%$. By polyp diameter, the one-bite polypectomy rate was $100 \%$, $96 \%, 88 \%$, and $70 \%$ for lesions up to $2,3,4$, and $5 \mathrm{~mm}$ in diameter, respectively. ${ }^{13}$ Despite the decrease to $70 \%$ at $5 \mathrm{~mm}$ complete resection could be achieved with 1 additional bite immediately afterward. ${ }^{13}$ No significant differences were found in the one-bite rate based on macroscopic type between flat and polypoid lesions. Also, there were no adverse complications such as post polypectomy bleeding or perforation. ${ }^{13}$ In addition, Kim et al. ${ }^{14}$ reported favorable results with a total polyp removal rate of $92 \%$ with CFP using biopsy forceps of standard capacity. These studies indicate that CFP is a simple and safe technique that can also retrieve all resected specimens for histological assessment.

Most reported studies of CFP have used standard capacity forceps rather than jumbo cup forceps. In this study, we prospectively enrolled patients with diminutive polyps for treatment with CFP using jumbo cup forceps to achieve an adenoma-free colon and assessed the safety of the procedure and the recurrence rate of missed or residual polyps after CFP by performing follow-up colonoscopy 1 year later.

\section{METHODS}

\section{Patients and Study Protocol}

From June 2015 to December 2017, CFP was performed for sessile and semi-pedunculated colon adenomas $5 \mathrm{~mm}$ or smaller at Shiga University of Medical Science Hospital. Study participants were 390 patients with 876 resected adenomas. We included patients who had up to 5 adenomas removed at the initial colonoscopy. After excluding 29 patients with familial adenomatous polyposis, hyperplastic polyps or sessile serrated polyp/adenoma, or 6 or more adenomas (Fig. 1), we analyzed data from 361 patients with 573 adenomas diagnosed on pathological examination and from 165 patients with 251 adenomas at the 1-year follow-up colonoscopy (Fig. 1).

Removal was determined based on magnifying NBI imaging along with observation of the resection site during the 1-year follow-up colonoscopy. For patients on antithrombotic therapy, CFP was performed based on the Japanese guidelines published by the Japan Gastroenterological Endoscopy Society. ${ }^{15}$ The bleeding risk of CFP was not determined in the guidelines. For endoscopic mucosal biopsy, withdrawal of aspirin, nonaspirin antiplatelet agents or anticoagulants is not required when the patient is on antithrombotic monotherapy. As for endoscopic mucosal resection, withdrawal of aspirin monotherapy is not required in patients who would be placed at high risk of thromboembolism by withdrawal. Basically, we

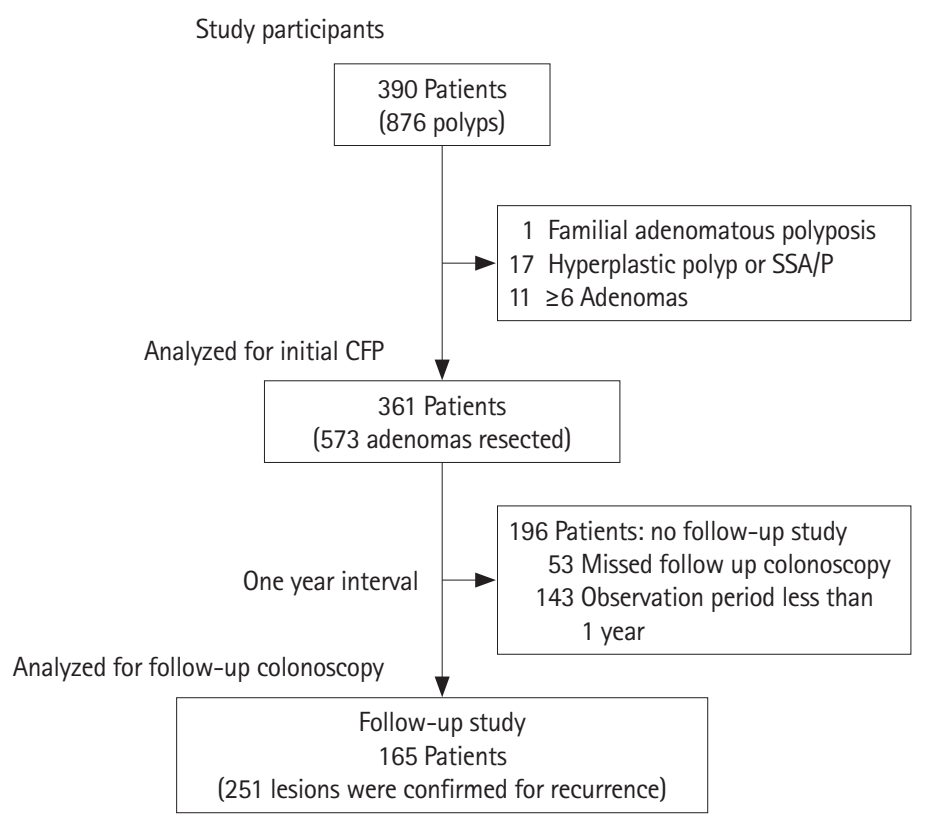

Fig. 1. Flowchart of the study participants. SSA/P, sessile serrated adenoma/polyp; CFP, cold forceps polypectomy. 
continued antithrombotic monotherapy for CFP.

The study was approved by the Ethics Committee of the Shiga University of Medical Science (approval number: 26-206). Informed consent for CFP was obtained at the time of consent for the colonoscopy and patients were accumulated prospectively.

\section{Definitions}

The main outcome of the study was to elucidate the recurrence rate of adenoma after CFP at 1 year. Definite recurrence was defined as (1) when a recurrent polyp was detected at the scar of the previous CFP in the same colorectal segment and/or (2) when a recurrent polyp was considered to occupy exactly the same site as a previous polyp by virtue of its relationship to obvious landmarks such as the appendiceal orifice and ileocecal valve. ${ }^{16}$ Probable recurrence was defined as recurrence in the same colorectal segment. We evaluated secondary outcomes including one-bite polypectomy rate based on adenoma diameter and factors associated with achievement of an adenoma-free colon, which was defined as no adenoma found at the 1-year follow-up colonoscopy. We also assessed the rate of complications such as bleeding and perforation. Post-polypectomy bleeding was defined as bleeding requiring endoscopic hemostasis within 30 days of polypectomy.

\section{Procedure}

The following protocol was used in performing CFP. A magnifying colonoscope (CF-260Z or PCF-260AZI; Olympus, Tokyo, Japan) was used. For CFP, the Radial Jaw ${ }^{\mathrm{TM}} 4$ Cold Polypectomy Forceps (Boston Scientific Corp., Marlborough, MA, USA) was used, which has a relatively large jaw outer diameter of 2.8 $\mathrm{mm}$, maximum opening of $8.8 \mathrm{~mm}$, and cup volume of 12.4 $\mathrm{mm}^{3}$ compared with standard forceps. After identification of the adenoma, shape, and size were determined under white light imaging. Lesion size was evaluated by laying the forceps next to it. The morphology of the polyp was described using Paris classification. ${ }^{17-19}$ The lesion was classified with NBI magnification using Sano's classification. ${ }^{20}$ The scope was handled to visualize the lesion at the 6 o'clock position of the scope image, and the forceps was rotated so it could be opened horizontally. To avoid perforation, the jumbo cups were opened just enough that the lesion would fit in the cup (half-opening). The adenoma with its basal mucosa was removed by fitting the lesion into the cup. The surrounding mucosa was cleaned after polyp removal and the absence of polyp remnants was confirmed by magnifying endoscopy with NBI, to complete the CFP procedure. When remnant adenoma was suspected, the area was further resected with the forceps to ensure there were no remnants.

\section{Statistical Analysis}

Analysis was performed by dividing the patients into those who had up to 2 adenomas removed at the initial colonoscopy

Table 1. Characteristics of the Patients and Resected Polyps

\begin{tabular}{|c|c|}
\hline Characteristics & Value \\
\hline Patient & 361 \\
\hline Sex (male/female) & $270 / 91$ \\
\hline Age at baseline colonoscopy (yr) & $70(63-75)$ \\
\hline Antithrombotic therapy (yes/no) & $45 / 316$ \\
\hline No. of adenomas $(\leq 2 / 3-5)$ & 293/68 \\
\hline Polyp & 573 \\
\hline \multicolumn{2}{|l|}{ Distribution } \\
\hline Cecum & $47(8)$ \\
\hline Ascending & $149(26)$ \\
\hline Transverse & $141(25)$ \\
\hline Descending & $60(10)$ \\
\hline Sigmoid & $133(23)$ \\
\hline Rectum & $43(8)$ \\
\hline \multicolumn{2}{|l|}{ Size $(m m)$} \\
\hline$\leq 3$ & $425(74)$ \\
\hline 4 & $115(20)$ \\
\hline 5 & $33(6)$ \\
\hline \multicolumn{2}{|l|}{ Morphology } \\
\hline $0-1 \mathrm{~s}$ & $153(26.7)$ \\
\hline 0 -Isp & $418(73.0)$ \\
\hline $0-\mid p$ & $2(0.3)$ \\
\hline \multicolumn{2}{|l|}{ Histology } \\
\hline Low-grade adenoma & $556(97)$ \\
\hline Low- to high-grade adenoma & $17(3)$ \\
\hline High-grade adenoma & 0 \\
\hline \multicolumn{2}{|l|}{ Forceps bites } \\
\hline 1 Bite & 506 (88) \\
\hline 2 Bites & $55(10)$ \\
\hline$>3$ Bites & $8(2)$ \\
\hline \multicolumn{2}{|c|}{ NBI classification (Sano's classification) } \\
\hline Type I & $42(7)$ \\
\hline Type II & 503 (88) \\
\hline Unclassified & $28(5)$ \\
\hline
\end{tabular}

Values are presented as median (interquartile range) or number (\%). $\mathrm{NBI}$, narrow band imaging. 
and those who had 3 to 5 adenomas removed. Also, the experience of the endoscopist at the time of initial colonoscopy was divided into 5 years or less or 6 years or more of experience. All statistical analyses were performed using Prism, version 6.05 (GraphPad, San Diego, CA, USA). The chi-square test was used for categorical data analysis. Logistic regression anal-

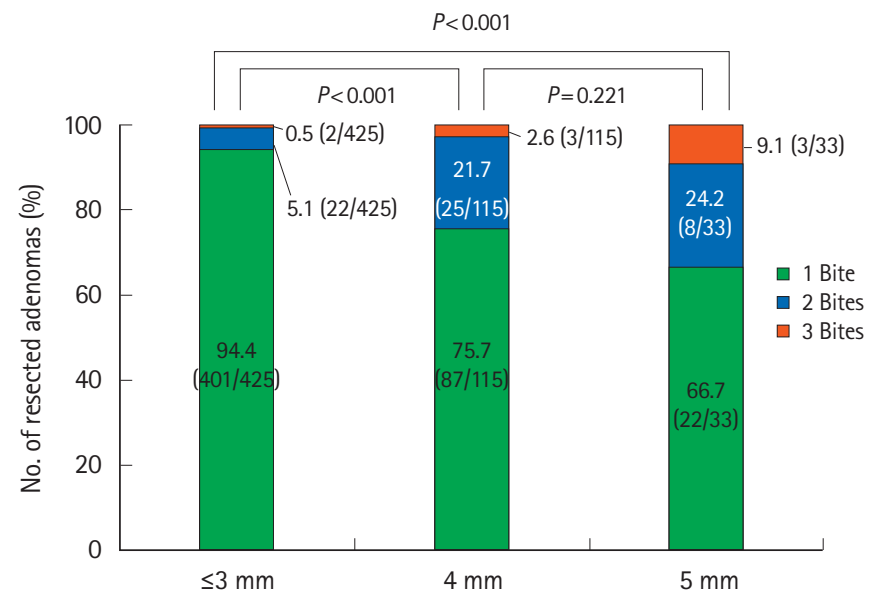

Fig. 2. One-bite resection rate and size of the adenoma. Chisquare test. ysis was performed to determine the factors affecting the achievement of an adenoma-free colon.

\section{RESULTS}

\section{Patients Characteristics and Initial CFP Results}

Table 1 shows the background and polyp characteristics of the patients in this study. Lesions $3 \mathrm{~mm}$ or smaller comprised $74 \%$ and were frequently noted in the ascending colon, transverse colon, and sigmoid colon. Also, the one-bite resection rate with CFP was highest for lesions $3 \mathrm{~mm}$ or smaller and the rate decreased significantly with increasing lesion size (Fig. 2). Most of the removed lesions were type II according to Sano's classification. Among the polyps resected in one-bite CFP, the positive rate of resection margin and the size of polyps were $0.25 \%$ (1/401) for $3 \mathrm{~mm}$ or smaller, 1.06\% (1/94) for $4 \mathrm{~mm}$ and $9.09 \%$ $(2 / 22)$ for $5 \mathrm{~mm}$. Including resection margin undetermined, the positive and undetermined rate of resection margin and the size of polyps were $15 \%$ (62/401) for $3 \mathrm{~mm}$ or smaller, $23 \%$ (22/94) for $4 \mathrm{~mm}$ and $36 \%$ (8/22) for $5 \mathrm{~mm}$. Post-procedural hemorrhage was observed in 1 of the 573 lesions $(0.17 \%)$, but

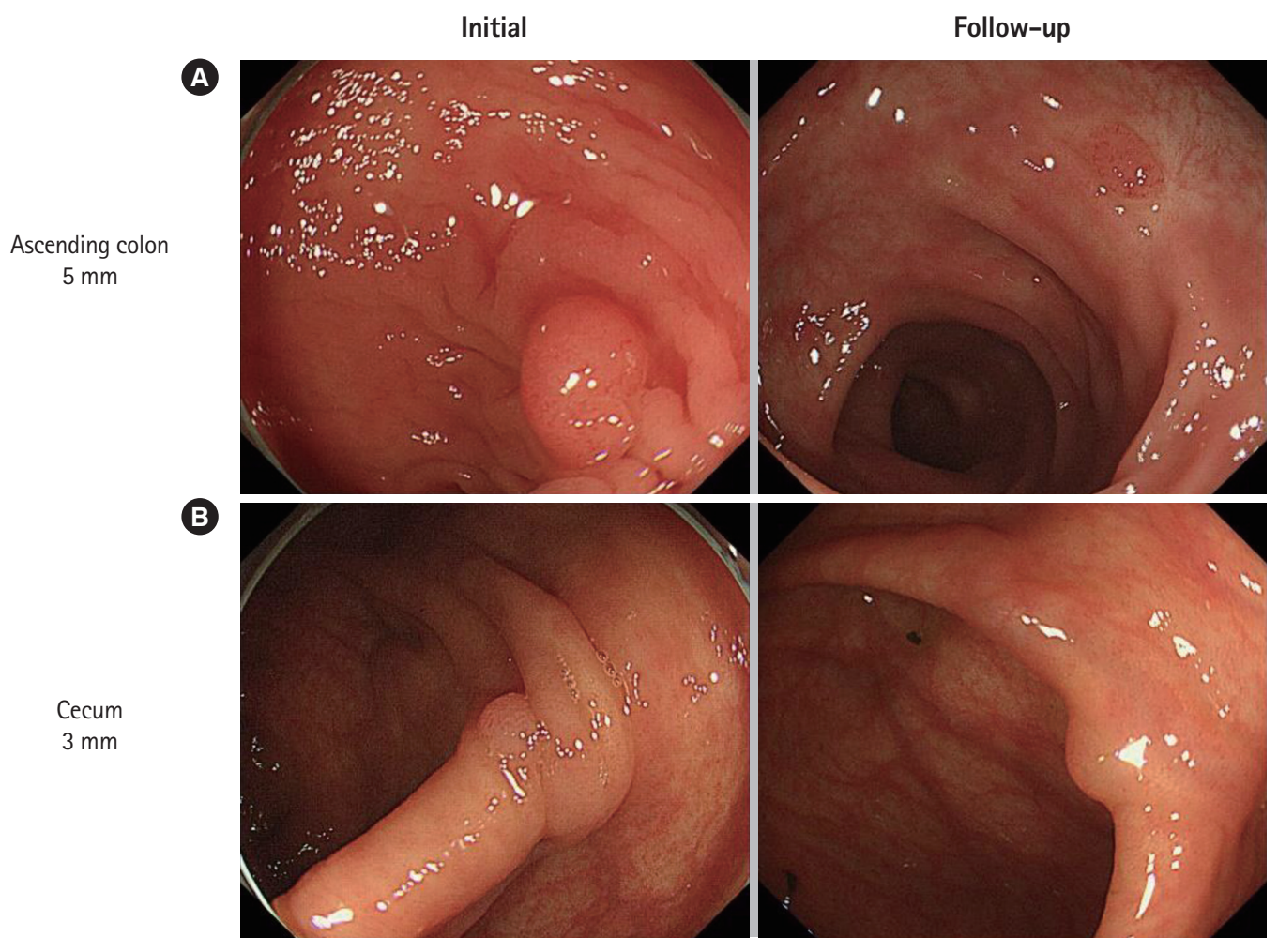

Fig. 3. Cases of definite recurrence. Recurrence of adenoma is noted in the same segment as the initial resection site. (A) Case 1:72-yearold male, Isp polyp, $5 \mathrm{~mm}$ in diameter was resected with one-bite cold forceps polypectomy. The pathology was low-grade adenoma. The resection margin was diagnosed as negative. (B) Case 2: 70-year-old male, Is polyp, $3 \mathrm{~mm}$ in diameter was resected with one-bite cold forceps polypectomy. The pathology was low-grade adenoma. The resection margin was undetermined. 
the patient was not on antithrombotic agents. No perforation was noted. All tissue samples were retrieved.

\section{Recurrence Rate of Individual Lesions (Definite Recurrence Rate)}

Of the 573 adenomas resected at the initial colonoscopy, 251 lesions were examined for definite recurrence at the 1-year follow-up. We found 2 adenomas with definite recurrence (Fig. 3 ), giving a definite recurrence rate of $0.8 \%$.

\section{Recurrence Rate of Individual Segments (Probable Recurrence Rate)}

In the 165 patients (251 lesions) who underwent follow-up colonoscopy 1 year later, adenomatous lesions were found in the same segment as the initially resected segment in $17 \%$ of patients (28/165). Adenomatous lesions were found in a different segment from the initial resection segment in $44 \%$ of patients $(72 / 165)$. The probable recurrence rate was $17 \%$ (42/251 lesions).

In patients with 2 or fewer adenomas removed at initial colonoscopy, new lesions in the same segment were noted in 15\% of patients (21/140) and in different segments in 39\% of patients (55/140), compared with $28 \%(7 / 25)$ and $68 \%(17 / 25)$ in patients with 3-5 adenomas removed (Fig. 4). The rate of

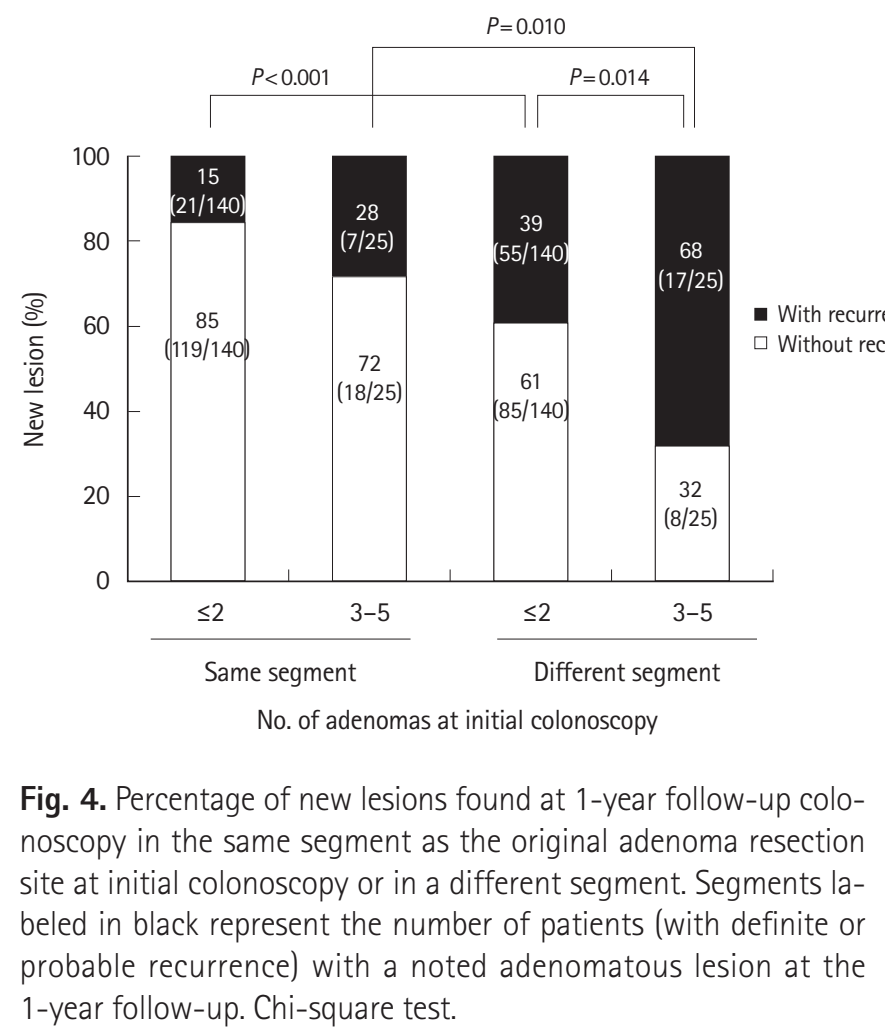

newly detected lesions in segments with adenomas found on initial examination was significantly lower compared with those found in different segments $(P<0.001$ for patients with 2 or fewer adenomas removed at initial colonoscopy, $P=0.010$ for patients with 3-5 adenomas removed, chi-square test) (Fig. 4). Also, the rate of new lesions in different segments was significantly lower in patients with 2 or fewer adenomas removed at the initial colonoscopy compared with patients with 3 to 5 adenomas ( $P=0.014$, chi-square test) (Fig. 4$)$.

\section{Rate of Achieving an Adenoma-Free Colon and Related Factors}

An adenoma-free colon was achieved in $55 \%$ of patients (90/ $165)$ at the initial resection. Total 116 polyps were discovered at follow-up colonoscopy. The number and size of missed polyps were $78(67 \%)$ for $3 \mathrm{~mm}$ or smaller, 18 (16\%) for $4 \mathrm{~mm}, 6$ (5\%) for $5 \mathrm{~mm}$ and 14 (12\%) for $6 \mathrm{~mm}$ or larger. The location of missed polyps was predominantly observed in ascending, transverse and sigmoid colon (Fig. 5). Patients in whom an adenoma-free colon was achieved at initial removal comprised 59\% of patients $(82 / 140)$ in the group with 2 or fewer lesions and in $32 \%(8 / 25)$ of the group with $3-5$ lesions; higher rates of achieving an adenoma-free colon were seen in the group with 2 or fewer lesions ( $P=0.025$, chi-square test). Multivariate logistic regression analysis to elucidate factors predicting an adenoma-free colon revealed that achievement of an adenoma-free colon was significantly related to number of adenomas and years of endoscopic experience (Table 2).

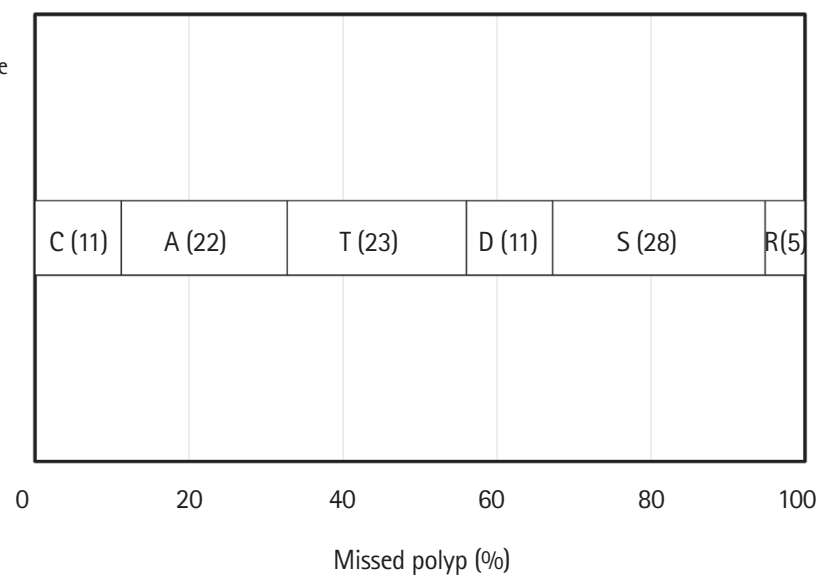

Fig. 5. Percentage of missed polyps in each segment at 1-year follow-up colonoscopy. $C$, cecum; $A$, ascending colon; $T$, transverse colon; $D$, descending colon; $S$, sigmoid colon; $R$, rectum. 
Table 2. Factors Affecting the Achievement of an Adenoma-Free Colon

\begin{tabular}{|c|c|c|c|c|}
\hline \multirow{2}{*}{ Factors obtained at baseline colonoscopy } & \multicolumn{2}{|c|}{ Univariate analysis } & \multicolumn{2}{|c|}{ Multivariate analysis } \\
\hline & $\mathrm{HR}(95 \% \mathrm{Cl})$ & $P$-value & $\mathrm{HR}(95 \% \mathrm{Cl})$ & $P$-value \\
\hline Endoscopists' years of experience ( $\leq 5 / \geq 6 \mathrm{yr}$ ) & $0.500(0.249-1.000)$ & 0.050 & $0.477(0.228-0.996)$ & $0.048^{a}$ \\
\hline Size of resected polyps ( $\leq 3 / 4-5 \mathrm{~mm})$ & $0.922(0.474-1.790)$ & 0.810 & $0.946(0.465-1.930)$ & 0.879 \\
\hline Patient age & $0.509(0.202-1.280)$ & 0.153 & $0.589(0.223-1.560)$ & 0.287 \\
\hline No. of resected polyps $(\leq 2 / 3-5)$ & $0.233(0.081-0.669)$ & $0.006^{\mathrm{a}}$ & $0.257(0.228-0.879)$ & $0.013^{\mathrm{a}}$ \\
\hline
\end{tabular}

Univariate and multivariate analyses were performed by logistic regression analysis.

${ }^{a}$ Statistically significant results.

\section{DISCUSSION}

Our results show that CFP using jumbo biopsy forceps is a safe procedure and is indicated for removing diminutive polyps 3 $\mathrm{mm}$ or smaller. The definite recurrence rate was as low as $0.8 \%$. Thus, CFP is an effective procedure to achieve an adenomafree colon. We also found that the number of adenomas at initial colonoscopy and years of endoscopic experience were significantly related to the achievement of an adenoma-free colon.

Most existing reports of CFP describe the use of standard capacity forceps with a maximum opening width of $7.3 \mathrm{~mm}$ or large capacity forceps with an opening width of $8.4 \mathrm{~mm}$. However, there are few reports on the use of jumbo cups with a maximum opening width of $8.8 \mathrm{~mm}$, as used in the present study. Aslan et al. ${ }^{21}$ and Draganov et al. ${ }^{22}$ conducted comparative studies of CFP using standard capacity forceps or large capacity forceps versus jumbo cup forceps and reported a significantly higher one-bite resection rate with the jumbo cup. In our study, the definite recurrence rate was $0.8 \%$. Lee et $\mathrm{al}^{23}$ used standard capacity forceps and reported a relatively high definite recurrence rate of $4 \%$. The difference may reflect not only the size of the biopsy forceps used, but also that $25 \%$ of our patients had polyps more than $3 \mathrm{~mm}$ in diameter compared with $47.5 \%$ of patients in Lee et al. ${ }^{23}$

One-year follow-up colonoscopy revealed newly detected lesions that included lesions missed at initial colonoscopy in $45 \%$ of patients. In reports by Winawer et al., ${ }^{6}$ Hirata et al., ${ }^{24}$ and Rex et al., ${ }^{25}$ the percentage of new lesions noted after initial total colonoscopy was reported to be $40 \%-50 \%$, which is comparable with our results. Repeat colonoscopy significantly reduces the number of missed lesions. ${ }^{24}$ Therefore, performing annual colonoscopy at least twice after polypectomy may minimize the incidence of missed lesions. ${ }^{24}$ Furthermore, location of the polyp is related to the missed lesions. We found new lesions predominantly in the ascending, transverse and sigmoid colon at the 1-year follow-up. This can be explained by morphology and anatomical structure with prominent folds leading to lower adenoma recognition. ${ }^{26}$

The rate of adenoma-free colon is affected mostly by polyps found in segments different from the initial colonoscopy. In addition, the substantial proportion of probable recurrence can be missed polyps. Combining them, the adenoma-free colon was not achieved by missed polyps. Therefore, we thought the factors affected the rate of adenoma-free colon is not related to the procedure itself.

Factors related to the adenoma detection rate (ADR) include observation time, ${ }^{27}$ use of improved devices, ${ }^{28}$ bowel preparation, ${ }^{29}$ and years of endoscopic experience. ${ }^{30}$ In our study, we did not evaluate observation time or extent of bowel preparation. Regarding the devices used, all of the enrolled patients underwent colonoscopy using a magnifying colonoscope (CFH260Z or PCF-260AZI), which had the same field view of $140^{\circ}$ without any cap attached to the tip. Therefore, the setting and devices used in this study are considered to be unified.

In terms of endoscopic experience, our study revealed a significantly lower rate of detection of new lesions at the 1-year follow-up when the initial colonoscopy was performed by an endoscopist with more than 5 years of experience. Similarly, Maratt et al. ${ }^{31}$ reported a lower ADR associated with a higher number of years since endoscopy training. On the other hand, Qayed et al. ${ }^{32}$ reported an increased ADR associated with more endoscopies performed during the training period. Our finding that experienced endoscopists had a higher ADR may be because the group of endoscopists with less than 5 years of experience included many who had examined fewer than 100 cases.

This study has several limitations. Firstly, it was conducted at a single institution, and thus may be influenced by selection bias. However, the examinations were performed by endoscopists with more than 5 years of experience as well as those with less than 5 years of experience. Therefore, any bias between 
endoscopists would be minimized. Secondly, we accumulated the patients prospectively, and only $76 \%$ of all patients could be followed up at 1 year. The presence of dropouts can be considered a limitation of this prospective study. We confirmed that there were no selection biases between patients with and without follow-up colonoscopy as shown in Supplementary Table 1. Thirdly, identification of the initial resection site at the time of follow-up was difficult and scar tissue formation was seen in only a few patients. We also used the distance between the location of the polyp and the anus to judge whether the new lesion is a residual lesion or not. Although the distance can be used as a reference, it is not an absolute indicator. In addition, we cannot rule out the possibility that there were residual lesions present that are too small to be observed by colonoscopy. Long-term follow-up may be needed.

In conclusion, CFP using jumbo biopsy forceps was safe and showed a high one-bite resection rate for diminutive lesions measuring $3 \mathrm{~mm}$ or smaller. New lesions were, however, noted on follow-up colonoscopy in approximately $50 \%$ of patients, and the rate of new lesions was significantly higher especially in patients with 3 or more adenomas at initial colonoscopy or when trainee endoscopists with 5 years of experience or less performed the procedure.

\section{FINANCIAL SUPPORT}

The authors received no financial support for the research, authorship, and/or publication of this article.

\section{CONFLICT OF INTEREST}

No potential conflict of interest relevant to this article was reported.

\section{AUTHOR CONTRIBUTION}

Conceptualization: Bamba S. Methodology: Bamba S. Formal analysis: Hasegawa H. Investigation: all authors. Writing - original draft: Hasegawa H. Writing - review and editing: Bamba S. Supervision: Andoh A. Approval of final manuscript: all authors.

\section{REFERENCES}

1. Ferlay J, Soerjomataram I, Ervik M, et al. Cancer incidence and mortality worldwide. GLOBOCAN 2012 v1.0. Lyon: Inter- national Agency for Research on Cancer, 2013.

2. O'Keefe SJ. Diet, microorganisms and their metabolites, and colon cancer. Nat Rev Gastroenterol Hepatol 2016;13:691-706.

3. Vogelstein B, Fearon ER, Hamilton SR, et al. Genetic alterations during colorectal-tumor development. N Engl J Med 1988;319:525-532.

4. Lieberman DA, Rex DK, Winawer SJ, Giardiello FM, Johnson DA, Levin TR. Guidelines for colonoscopy surveillance after screening and polypectomy: a consensus update by the US Multi-Society Task Force on Colorectal Cancer. Gastroenterology 2012;143:844-857.

5. Atkin WS, Valori R, Kuipers EJ, et al. European guidelines for quality assurance in colorectal cancer screening and diagnosis. First edition: colonoscopic surveillance following adenoma removal. Endoscopy 2012;44 Suppl 3:SE151-SE163.

6. Winawer SJ, Zauber AG, Ho MN, et al. Prevention of colorectal cancer by colonoscopic polypectomy: the National Polyp Study Workgroup. N Engl J Med 1993;329:1977-1981.

7. Zauber AG, Winawer SJ, O'Brien MJ, et al. Colonoscopic polypectomy and long-term prevention of colorectal-cancer deaths. N Engl J Med 2012;366:687-696.

8. Jung YS, Park JH, Kim HJ, et al. Complete biopsy resection of diminutive polyps. Endoscopy 2013;45:1024-1029.

9. Pohl H, Srivastava A, Bensen SP, et al. Incomplete polyp resection during colonoscopy-results of the complete adenoma resection (CARE) study. Gastroenterology 2013;144:74-80.e1.

10. Gómez V, Badillo RJ, Crook JE, Krishna M, Diehl NN, Wallace MB. Diminutive colorectal polyp resection comparing hot and cold snare and cold biopsy forceps polypectomy. Results of a pilot randomized, single-center study (with videos). Endosc Int Open 2015;3:E76-E80.

11. Ikematsu H, Matsuda N, Sano Y, et al. Management of polyps less than $10 \mathrm{~mm}$ : data from the Japan Polyp Study. Intestine 2016;20:457-462.

12. Lee YC, Li-Sheng Chen S, Ming-Fang Yen A, et al. Association between colorectal cancer mortality and gradient fecal hemoglobin concentration in colonoscopy noncompliers. J Natl Cancer Inst 2017;109:djw269.

13. Uraoka T, Ramberan H, Matsuda T, Fujii T, Yahagi N. Cold polypectomy techniques for diminutive polyps in the colorectum. Dig Endosc 2014;26 Suppl 2:98-103.

14. Kim JS, Lee BI, Choi H, et al. Cold snare polypectomy versus cold forceps polypectomy for diminutive and small colorectal polyps: a randomized controlled trial. Gastrointest Endosc 2015;81:741-747.

15. Fujimoto K, Fujishiro M, Kato M, et al. Guidelines for gastro- 
enterological endoscopy in patients undergoing antithrombotic treatment. Dig Endosc 2014;26:1-14.

16. Lee HS, Park HW, Lee JS, et al. Treatment outcomes and recurrence following standard cold forceps polypectomy for diminutive polyps. Surg Endosc 2017;31:159-169.

17. Endoscopic Classification Review Group. Update on the paris classification of superficial neoplastic lesions in the digestive tract. Endoscopy 2005;37:570-578.

18. The Paris endoscopic classification of superficial neoplastic lesions: esophagus, stomach, and colon: November 30 to December 1, 2002. Gastrointest Endosc 2003;58(6 Suppl):S3-S43.

19. Japanese Gastric Cancer Association. Japanese classification of gastric carcinoma: 2nd English edition. Gastric Cancer 1998; 1:10-24.

20. Sano Y, Ikematsu H, Fu KI, et al. Meshed capillary vessels by use of narrow-band imaging for differential diagnosis of small colorectal polyps. Gastrointest Endosc 2009;69:278-283.

21. Aslan F, Cekiç C, Camci M, et al. What is the most accurate method for the treatment of diminutive colonic polyps? Standard versus jumbo forceps polypectomy. Medicine (Baltimore) 2015;94:e621.

22. Draganov PV, Chang MN, Alkhasawneh A, et al. Randomized, controlled trial of standard, large-capacity versus jumbo biopsy forceps for polypectomy of small, sessile, colorectal polyps. Gastrointest Endosc 2012;75:118-126.

23. Lee CK, Shim JJ, Jang JY. Cold snare polypectomy vs. cold forceps polypectomy using double-biopsy technique for removal of diminutive colorectal polyps: a prospective randomized study. Am J Gastroenterol 2013;108:1593-1600.

24. Hirata I, Yasumoto S, Nishikawa T, Toshina K. Optimal follow- up program after colonoscopic removal of colorectal neoplasia. J Jpn Soc Coloproctol 2006;59:880-884.

25. Rex DK, Cutler CS, Lemmel GT, et al. Colonoscopic miss rates of adenomas determined by back-to-back colonoscopies. Gastroenterology 1997;112:24-28.

26. Aranda-Hernández J, Hwang J, Kandel G. Seeing better: evidence based recommendations on optimizing colonoscopy adenoma detection rate. World J Gastroenterol 2016;22:17671778.

27. Barclay RL, Vicari JJ, Doughty AS, Johanson JF, Greenlaw RL. Colonoscopic withdrawal times and adenoma detection during screening colonoscopy. N Engl J Med 2006;355:2533-2541.

28. Castaneda D, Popov VB, Verheyen E, Wander P, Gross SA. New technologies improve adenoma detection rate, adenoma miss rate, and polyp detection rate: a systematic review and metaanalysis. Gastrointest Endosc 2018;88:209-222.e11.

29. Clark BT, Protiva P, Nagar A, et al. Quantification of adequate bowel preparation for screening or surveillance colonoscopy in men. Gastroenterology 2016;150:396-405.

30. Kang HY, Kim D, Kim HJ, et al. The relationship between colonoscopy procedure order and adenoma detection rates: a prospective study. J Clin Gastroenterol 2015;49:683-689.

31. Maratt JK, Dickens J, Schoenfeld PS, et al. Factors associated with surveillance adenoma and sessile serrated polyp detection rates. Dig Dis Sci 2017;62:3579-3585.

32. Qayed E, Vora R, Levy S, Bostick RM. Colonoscopy procedural volume increases adenoma and polyp detection rates in gastroenterologytrainees. World J Gastrointest Endosc 2017;9: 540-551. 
See "Efficacy and safety of cold forceps polypectomy utilizing the jumbo cup: a prospective study" on page $265-272$.

Supplementary Table 1. Comparison of Clinical Backgrounds of Patients with and without Follow-up Colonoscopy

\begin{tabular}{lccc}
\hline Patient characteristics & With follow-up & Without follow-up & $P$-value \\
\hline Sex (male/female) & $101 / 64$ & $36 / 17$ & $0.473^{\mathrm{a}}$ \\
Age at baseline colonoscopy (yr) & $69(63-74)$ & $67(56-75)$ & $0.354^{\mathrm{b}}$ \\
Antithrombotic therapy (yes/no) & $26 / 139$ & $6 / 47$ & $0.568^{\mathrm{a}}$ \\
No. of adenomas ( $\leq 2 / 3-5)$ & $139 / 26$ & $44 / 9$ & $1.000^{\mathrm{a}}$ \\
\hline
\end{tabular}

Values are presented median (interquartile range).

${ }^{a}$ Chi-square test.

${ }^{b}$ Mann-Whitney test. 